\title{
Study on Dry Sliding Wear Characteristics by Taguchi Analysis of Al- Mg-Si-Cu-SiC Composite Prepared by Powder Metallurgy Method
}

\author{
Rajesh Kumar Behera, ${ }^{1, *}$, Birajendu Prasad Samal', \\ Ajit Kumar Khatua ${ }^{3}$ and Sarat Chandra Panigrahi ${ }^{4}$ \\ ${ }^{I}$ Research Scholar, Biju Patnaik University of Technology, Rourkela, Odisha, India \\ ${ }^{2}$ Department of Mechanical Engineering, Orissa Engineering College, Bhubaneswar, Odisha, India \\ ${ }^{3}$ Department of Mechanical Engineering, Vignana Bharathi Institute of Technology, Aushapur, \\ Ghatkesar, Hyderabad, Telangana, India \\ ${ }^{4}$ Indian Institute of Technology Kharagpur, Raajdhani Engineering College, Bhubaneswar, Odisha, India
}

(Corresponding author's e-mail: rajesh_k_behera@yahoo.co.in)

Received: 17 February 2021, Revised: 25 May 2021, Accepted: 2 June 2021

\begin{abstract}
There is a growing attention among researchers to the production of new composites with lowdensity and low-cost processes. Aluminum based metal-matrix composites (AMMC) offer solutions for new product development. In this paper, a newly developed $\mathrm{Al}-\mathrm{Mg}-\mathrm{Si}-\mathrm{Cu}-\mathrm{SiC}$ composite was manufactured by powder-metallurgy, and the wear mechanism of aluminum composite materials was carried out using the pin-on-disk method. The purpose of the experimental plan was to correlate the factors that influenced the wear operations in order to execute them with a minimal rate of wear and coefficient of friction (COF). The experiment was based on the Taguchi design with OA (orthogonal arrays) to correspond to the effects of load applied, sliding speed, and distance. The design features are distinctive and integral attributes of the method, affecting and determining the wear characteristics of composites. The predictive models developed for various machining performance characteristics employing response surface methodology are effective in terms of adequate, statistically significant, and probabilistically validate because of their higher $\mathrm{R}^{2}$-values, $P$-values less than 0.05 and larger AD-test $p$ values. The data generated for the Al-Mg-Si-Cu-SiC AMMC will be useful for the industry.
\end{abstract}

Keywords: Aluminum metal matrix composites, Analysis of variance, Co-efficient of friction, Powder metallurgy, Taguchi technique, Wear

\section{Introduction}

Due to the introduction of high-performance and lightweight aluminum metal matrix composites (AMMC) for the automotive, aerospace, and consumer markets, it was possible to achieve a uniform distribution of reinforcements within a matrix element while producing usable, superior quality composite materials. The most commonly used composite system with the metal matrix aluminum reinforced with silicon carbide, magnesium, copper, and silicon prepared an aluminum-metal matrix composite through powder metallurgy (PM), which is a new variety of composite material having required properties like less density, high stiffness and strength, good thermal coefficient of expansion, better fatigue resistivity and excellent stable dimension at elevated temperatures [1-3]. An aluminum-alloy has excellent mechanical properties such as low density, higher thermal conductivity, strength to weight ratio, good ductility, and corrosion resistance, among others [4]. Aluminum-alloys have high strength and are used in aeronautics as well as all automotive sectors. The addition of $\mathrm{SiC}$ to matrix aluminum improves strength and mechanical-thermal properties. The hard reinforcement of $\mathrm{SiC}$ particles increased the high-hardness and wear resistance of the composite used for load sustaining components [5]. In the stir-casting method, the ceramic reinforcement, i.e., silicon carbide melted with aluminum metal-matrix, achieved improved properties of the composites [6]. All mechanical components that slide or roll, like brakes and clutches, bearings, piston rings, terrain, gears, guides, and seals, are exposed to wear.

A significant decrease in corrosive wear and wear rate (WR) was experienced in $\mathrm{FGC} \mathrm{Cu}, \mathrm{Cu}$ and $\mathrm{Cu}-\mathrm{SiC}$. $\mathrm{Cu}, \mathrm{Cu}-\mathrm{SiC} \mathrm{FGC}$ was more corrosion-resistant than $\mathrm{Cu}-\mathrm{FGC}$ at high-load, $10 \mathrm{~N}$, while the second one showed lower WR at lower loads, 20N [7]. The hybrid aluminum-matrix-composite reinforced with 
$\mathrm{Y}_{2} \mathrm{~W}_{3} \mathrm{O}_{12}$ (yttrium-tungsten) and (AIN) aluminum nitride was noted as a high hardness composite, a high Young's modulus and a low-CTE coefficient could be found by adding $15 \%$ by weight AlN and also $30 \%$ by weight $\mathrm{Y}_{2} \mathrm{~W}_{3} \mathrm{O}_{12}$ in matrix $\mathrm{Al}$ [8]. The reinforced aluminum composite with the reinforced particles of $\mathrm{Al}_{2} \mathrm{O}_{3}$ and $\mathrm{Al}_{3} \mathrm{Zr}$ was made from metal powder and the results of dry sliding wear-tests clearly indicated that increasing the portion size of zirconium particles in the composite materials improved the wear resistance [9]. The WR of the nano-composites increases with increased load, while it decreases with increasing sliding speed. The friction coefficient also improves with an increase in the sliding speed. Moreover, with the variation of load, this appears as a minimum in inter-mediate load. The formed composite showed the lowest WR and COF, with the exception of the highest tested load [10]. However, the abrasive-wear behavior of hybrid composites based on Al-4.5\% by weight $\mathrm{Cu}$ enhanced by zircon sand and SiC particles was found to wear mainly due to surface ploughing when scraping silicon-carbide particles [11]. The tribological properties of aluminum-copper/SiC matrix composites improve as their mechanical properties improve; wear resistance improves dramatically, affecting the composite [12]. The sliding-wear behavior of $10 \%$ by weight $\mathrm{SiC}$-supported aluminum composites produced by the Vortexmethod, with the help of a pin-on-disc wear-test machine greatly improved the wear-resistance [13] and the dry sliding wear behavior of Al-2219 alloys reinforced with SiC particles at 0 to15\% wt. The WR is less than the matrix alloy and decreases more with a higher $\mathrm{SiC}$ content [14]. With $7.5 \% \mathrm{SiCp}$ in the composite, the sliding-time has the most significant contribution to controlling the COF and wear behavior of aluminum, and proper control of process-parameters reveals that Taguchi analysis can result in optimal mixing of process-parameters for minimal friction and wear [15]. The wear-resistance of the composites was much higher and increased as the proportion of $\mathrm{SiC}$ particles increased and decreased as the grain size of the abrasive-grit [16]. The influence of the volume-fraction, size of reinforcement, sliding distance, sliding speed, load, working-surface hardness and reinforcement phase properties would affect the wear characteristics when sliding in the dry state of this group of composites and the wear parameters affect the sliding speed and wear characteristics [17, 18] and in the WR of a zinc-based SiC composite would increase in load of dry and oil lubricated conditions. Silicon-carbide reinforcement would reduce the composite WR [19]. Pin-on-disc wear-tests which were better for UNS-A92024-T (Aluminum-Copper) alloy and WC-Co (tungsten carbide) (WC-Co)[20]. The fiber-reinforcement remarkably improved the wear resistance of the composites, which was equal to or lower than that of the un-reinforced material [21]. The sliding distance is the most important variable for WR of an AA7050 aluminum-alloy with SiC-reinforced percentages $(0,4$ and $6 \%$ which was analyzed through the DOE (Taguchi design) to optimize the process-parameters of sliding-velocity $(1,2$ and $3 \mathrm{~m} / \mathrm{s})$, sliding distance of 1000, 1400 and $1800 \mathrm{~m}$ and percentage of compositions are of 0,3 and $6 \%$ [22].

An optimal-value of control variables in COF and WR for (silicon-carbide and boron-carbide) reinforced Al matrix-composites were examined by RSM (response surface methodology) with $1.5 \mathrm{~m} / \mathrm{s}$ of sliding speed, $20 \mathrm{~N}$ of load, $6 \mathrm{wt} \%$ of reinforcement, and $1000 \mathrm{~m}$ of sliding distance, which resulted in the minimum WR [23]. The COF and WR of aluminum-composites with SiC reinforcement having 3 different parameters. Dry-medium, aqueous-medium, and alkaline-medium were tested with a tribo-tester (pin-on-disk). The WR improves with an increase in load and sliding speed. The wear was found to be minimum in the dry condition as compared to the other two and also, the COF decreased with an increase in load [24]. The wear-behavior of Al-alloys using a pin-on-disc apparatus was investigated. The wear resistance of hypo-eutectic and eutectic phases increased with the addition of grain modifier [25]. The AA6061 matrix composites with ceramic reinforced (alumina, boron-carbide, and silicon-carbide) would enhance the resistance to wear in the hot-pressing process. The WR and volume-loss increase with increasing sliding distance and normal load [26], and the rate of wear decreases linearly as compared to increasing $\mathrm{wt} \%$ of $\mathrm{SiC}$ and $\mathrm{COF}$ decreases linearly with increasing normal-load and $\mathrm{wt} \%$ of $\mathrm{SiC}$ [27]. The wear and COF characteristics of the Al-SiC-MWCNT composite were greatly influenced by load and had a negative impact on the wear when the load was critical, and the hardness of the matrix composite was increased with increasing reinforcement percent [28]. The WR had the greatest impact on the load (62.11 $\%)$, then the sliding speed $(32.88 \%)$, and the least the sliding distance $(2.57 \%)$. They verified by the design method of Taguchi that the specific WR of A356 aluminum alloy with $10 \%$ SiC by weight and 1 $\%, 5 \% \mathrm{Gr}$ by weight decreases with minimum load, sliding speed, and Graphite reinforcement [29, 30]. MMC has excellent engineering-properties and wear [31]. The design of the experimental approach (DOE) using the Taguchi method was used to anticipate the behavior of wear against variable-parameters like load, sliding speed and sliding duration [32]. The simulated result of the ANOVA analysis discovered that the applied- load has greater importance in the WR, followed by the temperature and the sliding speed, and with increasing load and temperature, the WR of the hybrid-composite also increases. Furthermore, increasing the speed reduces the WR [33] and an OA and ANOVA were used to find the 
effect of wear-parameters such as sliding distance, load and sliding speed on dry sliding wear of the composites [34]. The Taguchi design method was used to find the smallest WR and COF values in an AlSi alloy (A356) matrix-composites reinforced with $10 \mathrm{wt} \% \mathrm{SiC}$ and 0,1 , and $3 \mathrm{wt} \%$ Gr with optimizing ANOVA, but the hybrid composites with $3 \mathrm{wt} \% \mathrm{Gr}$ will have the smallest wear and COF values [35].

Light metal-matrix composites are synthesized from mixtures of elemental aluminum powder. Aluminum composites are in great demand in the industry because of their light weight, wear resistance, rigidity, and high strength. The novel contribution of this paper is to provide systematic approaches and Taguchi methodology that improve the dry sliding wear characteristics of the Al-Mg-Si-Cu-SiC composite at various loads and sliding speeds. Using the Taguchi-optimization method, it is more expedient to obtain the minimum WR of the composites. This has been proved in the current research by Taguchi analysis, which shows that the $\mathrm{SiC}$ particulate reinforcement along with $\mathrm{Cu}, \mathrm{Mg}$ and $\mathrm{Si}$ is one of the methods for increasing the wear-resistance of composites over the existing ones.

\section{Materials and methods}

\section{Raw materials}

Metal powders were selected and purchased from commercial sources for conducting the experiment to produce the $\mathrm{Al}-\mathrm{Mg}-\mathrm{Si}-\mathrm{Cu}-\mathrm{SiC}$ composite. The powder particles that were used to make the composite had the following chemical analysis, shown in Table 1.

Table 1 Chemical analysis report of metal powders.

\begin{tabular}{cccccccc}
\hline $\begin{array}{c}\text { Powder } \\
\text { element }\end{array}$ & $\begin{array}{c}\text { Atomic } \\
\text { number }\end{array}$ & $\begin{array}{c}\text { Density } \\
\left(\mathbf{g m} / \mathbf{c m}^{\mathbf{3}}\right)\end{array}$ & $\begin{array}{c}\text { Atomic } \\
\text { mass (u) }\end{array}$ & $\begin{array}{c}\text { Melting } \\
\text { point }\left(\mathbf{(}^{\mathbf{0}} \mathbf{C}\right)\end{array}$ & $\begin{array}{c}\text { Purity } \\
\mathbf{( \% )}\end{array}$ & $\begin{array}{c}\text { Used } \\
\text { form }\end{array}$ & $\begin{array}{c}\text { Particle } \\
\text { size } \\
(\mathbf{m e s h})\end{array}$ \\
\hline $\mathrm{Al}$ & 13 & 2.70 & 26.981539 & 660.3 & 99.55 & powder & 325 \\
$\mathrm{Mg}$ & 12 & 1.738 & 24.305 & 650 & 99.87 & powder & 100 \\
$\mathrm{Si}$ & 14 & 2.329 & 28.0885 & 1414 & 99.87 & powder & 325 \\
$\mathrm{Cu}$ & 29 & 8.96 & 63.546 & 1085 & 99.77 & powder & 325 \\
$\mathrm{SiC}$ & - & 3.21 & - & 2730 & 99.92 & powder & 325 \\
\hline
\end{tabular}

\section{AMMC production}

In the present study, the PM product preparation method was adopted to produce AMMC, and the metal powder reinforcement was added to the matrix. The aluminum powders used as the main raw material are called, the matrix materials, and have been reinforced with $\mathrm{Cu}, \mathrm{Mg}, \mathrm{Si}, \mathrm{SiC}$ powders. The Al$0.5 \mathrm{Si}-0.5 \mathrm{Mg}-2.5 \mathrm{Cu}-10 \mathrm{SiC}$ composite material was prepared on a weight basis, stating;

a) the choice of metal powders

b) weighing

c) blending/mixing

d) compressive pressing

e) and sintering

The AMMCs were reinforced by $10 \mathrm{wt} \%$ of $\mathrm{SiC}$ and the mixture powders were compacted inside a metal (C-45 steel) die with a digital compression test machine. The compacted green samples were recovered from the die and sintered in a muffle type furnace. The sintering furnace temperature was maintained at about $620{ }^{\circ} \mathrm{C}$ and the green samples were annealed for $24 \mathrm{~h}$. The various process steps in AMMC production are shown in Figures 1(a) - 1(d). 


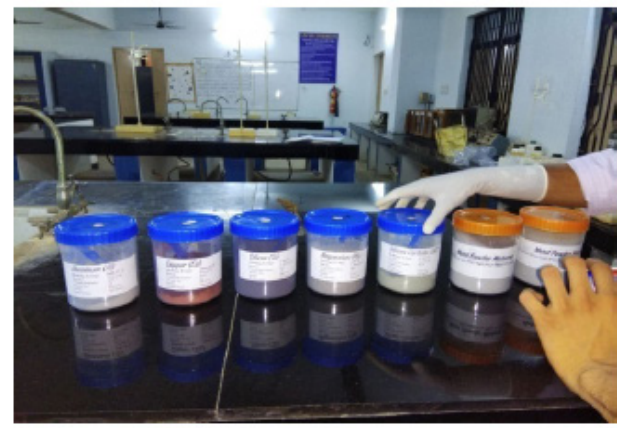

(a) Metal powders Collections.

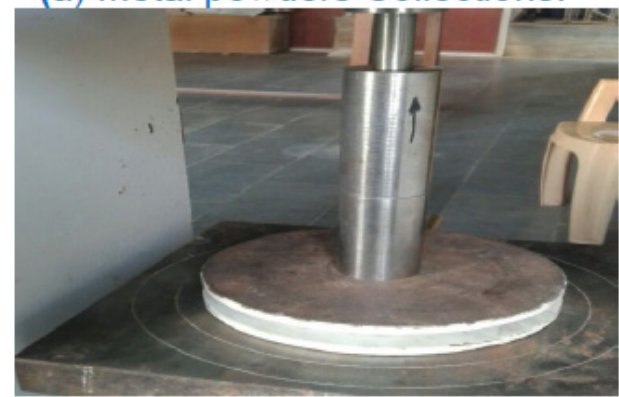

(c) Powder mixture Compaction.

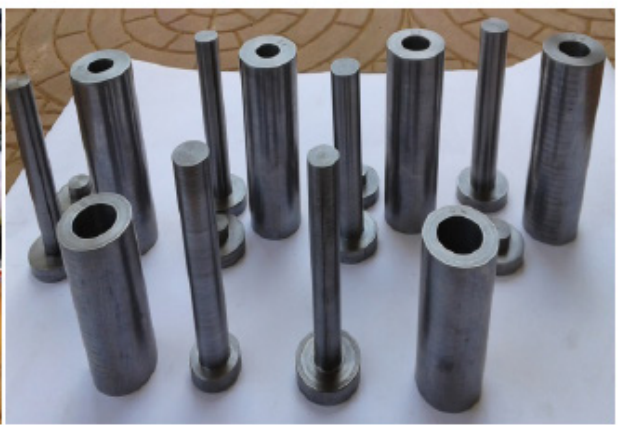

(b) C-45 steel dies manufacture.

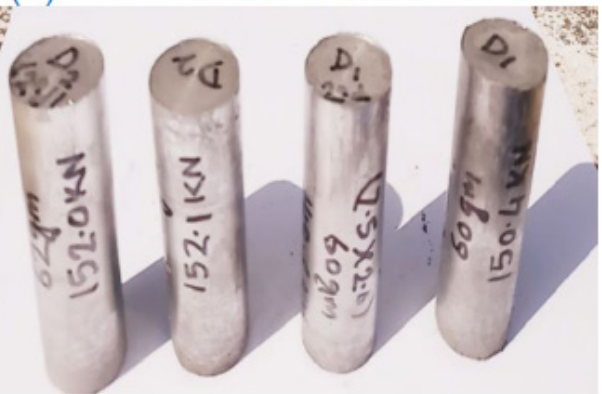

(d) Final Sintered products.

Figure1 Stepwise AMMC production process.

\section{Sample preparations}

The sample specimens of the Al-0.5Si-0.5Mg-2.5Cu-10SiC composite were cut for wear testing. The test was conducted in accordance with ASTM G99 standards. Samples of $30 \times 10 \mathrm{~mm}^{2}$ were machined and polished and processed further for the dry sliding wear test. The pin-on-disk testing apparatus was utilized to observe the wear-characteristics of the matrix-composite aluminum material.

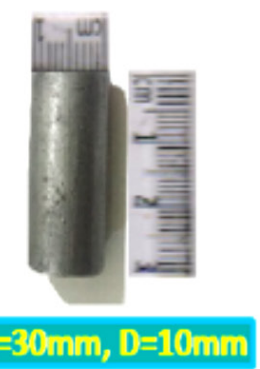

Sample for the wear test

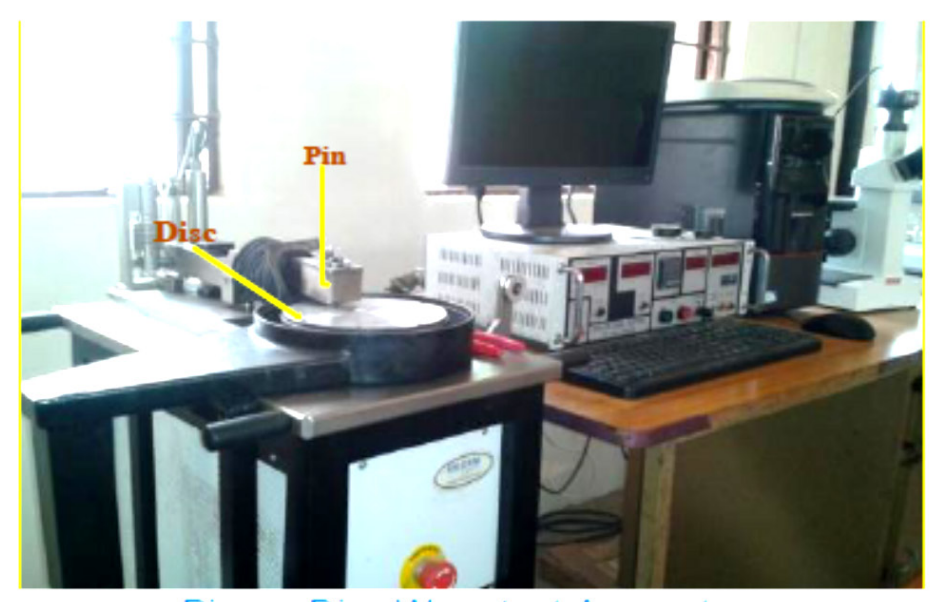

Pin-on-Disc Wear test Apparatus

Figure2 Sample and pin-on-disc wear-test apparatus for the wear-test.

\section{Wear test experimental procedures (by pin-on-disc method)}

The dry sliding wear test was performed using a pin-on-disc tribometer (Make: DUCOM) and a prepared sample as shown in Figure 2 for the composite material. Before starting the test, the surfaces of the pin and disc were polished with a fine emery sheet. The sample was clamped and held on to a steel disc during the test. All the tests were performed under dry sliding conditions at a normal ambient temperature. The load was applied to the samples through a cantilever mechanism with a tracking radius. Before and after the specimens were noted-down for each test, they were measured with an electronicweighing device of accuracy of $0.0001 \mathrm{gm}$. The weight loss in the sample occurred after measures were 
taken to ensure continuous cleaning of the test samples to escape contamination during experiments. The pin-on-disk testing apparatus was used to calculate the dry sliding wear characteristics of each of the Alcomposite test samples.

The contacting surfaces of each of the composite samples were made flat because they should be in proper contact with the rotating disk. In addition, the samples before and after the experiment were thoroughly cleaned with an acetone solution. The computer base testing machine directly shows the coefficient friction (COF). The experiment was done with the parameters of different sliding speeds like 2, 4 and $6 \mathrm{~m} / \mathrm{s}$, applied loads of 20,30, and $40 \mathrm{Nm}$ and sliding distances of 1000, 2000 and $3000 \mathrm{~m}$. The WR is calculated as:

$W_{r}=\frac{\Delta w}{\rho \times L}$

where $\mathrm{W}_{\mathrm{r}}=$ wear rate $\left(\mathrm{mm}^{3} / \mathrm{m}\right), \Delta \mathrm{w}=$ weight loss $(\mathrm{gm}), \rho=\operatorname{density}\left(\mathrm{gm} / \mathrm{mm}^{3}\right), \mathrm{L}=$ sliding distance $(\mathrm{m})$.

\section{Results and discussion}

\section{Microstructure}

The microstructure of the composite material was shown in Figure3 before and after the wear test. The dry-sliding wear for the manufactured AMMC was made for a fixed sliding distance of $1000 \mathrm{~m}$ at various sliding speeds of 2, 4 and $6 \mathrm{~m} / \mathrm{s}$ at 3 different loads of 20,30 and $40 \mathrm{~N}$. The different WR is shown in Table 2. The dry sliding wear test of the manufactured AMMC had sliding distances with different sliding speeds of 2, 4and $6 \mathrm{~m} / \mathrm{s}$ with 3 different loads of 20 and 30 and $40 \mathrm{~N}$. The WR are expressed in Table 2. The worn surface of the composite-material test samples clearly shows the presence of deep fixed grooves and shows subtle grooves of soft deformation at the edges of the grooves shown in Figure 3(b). The surface also looks smooth due to the reinforcement content. The worn surfaces of the AMMCs have been found with fine scratches. The wear mechanisms were characterized by the appearance of the grooves, which were formed by the cracking process of the hard sharpness on the opposite disc with worn, hardened debris. So, the increase in silicon carbide will lead to a decrease in wear.
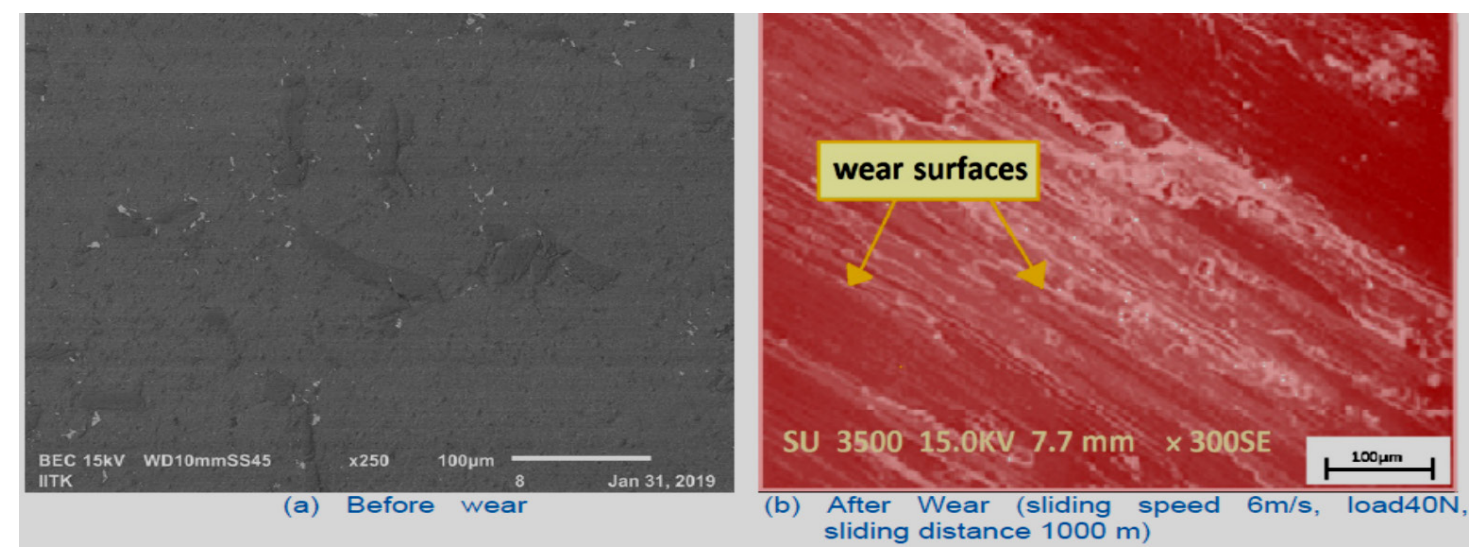

Figure3 SEM images of the Al-0.5Si-0.5Mg-2.5Cu-10\% SiC composite before and after wear.

\section{Hardness}

The sample (PIN) hardness was measured with a Vickers hardness-testing instrument with a load of $5 \mathrm{~N}$ and retention time of $10 \mathrm{~s}$. The hardness (Vickers) of AMMC Al-0.5Si-0.5Mg-2.5Cu-10SiC was conducted across the cross section and tabulated in Table 2. Then after polishing, the surface roughness of sample (PIN) cross section was measured and found outto be $\mathrm{R}_{\mathrm{a}}=5.68 \mu \mathrm{m}$. 
Table 2 Hardness test of AMMC sample (PIN) along the cross section before wear test.

\begin{tabular}{ccccc}
\hline $\begin{array}{c}\text { Distance from one end along the diameter } \\
\text { of sample cross section }\end{array}$ & \multicolumn{4}{c}{ Hardness(HV) } \\
\hline At a distance & Test-1 & Test-2 & Test-3 & Average \\
2mm & 214.1 & 211.3 & 212.5 & 212.6 \\
$4 \mathrm{~mm}$ & 213.3 & 212.5 & 211.1 & 212.3 \\
$6 \mathrm{~mm}$ & 213.2 & 213.6 & 212.8 & 213.3 \\
8mm & 212.4 & 212.9 & 210.1 & 211.8 \\
Average hardness ofsample (PIN) & & & & 212.5 \\
\hline
\end{tabular}

\section{Wear test}

A dry sliding wear test of an aluminum composite was conducted to find the WR with different loads $(20,30$ and $40 \mathrm{~N})$ and with different sliding speeds $(2,4$ and $6 \mathrm{~m} / \mathrm{s})$. Three experiments were conducted for loads of 20,30 and $40 \mathrm{~N}$ with sliding velocities of 2,4 and $6 \mathrm{~m} / \mathrm{s}$ for a fixed sliding distance of $1000 \mathrm{~m}$ and the results are mentioned in Table 3 .

Table 3 WR with different sliding speed.

\begin{tabular}{ccccccc}
\hline $\begin{array}{c}\text { Load } \\
(\mathbf{N})\end{array}$ & $\begin{array}{c}\text { Sliding speed } \\
(\mathbf{m} / \mathbf{s})\end{array}$ & $\begin{array}{c}\text { Wear rate } \\
\left(\mathbf{m m}^{\mathbf{3}} \mathbf{m}\right)\end{array}$ & $\begin{array}{c}\text { Sliding speed } \\
\mathbf{( \mathbf { m } / \mathbf { s } )}\end{array}$ & $\begin{array}{c}\text { Wear rate } \\
\left(\mathbf{m m}^{\mathbf{3}} / \mathbf{m}\right)\end{array}$ & $\begin{array}{c}\text { Sliding speed } \\
(\mathbf{m} / \mathbf{s})\end{array}$ & $\begin{array}{c}\text { Wear rate } \\
\left(\mathbf{m m}^{\mathbf{3}} / \mathbf{m}\right)\end{array}$ \\
\hline 20 & 2 & 1.3837 & 4 & 1.4326 & 6 & 1.4916 \\
30 & 2 & 1.5219 & 4 & 1.5722 & 6 & 1.6938 \\
40 & 2 & 1.8123 & 4 & 1.9256 & 6 & 2.3416 \\
\hline
\end{tabular}

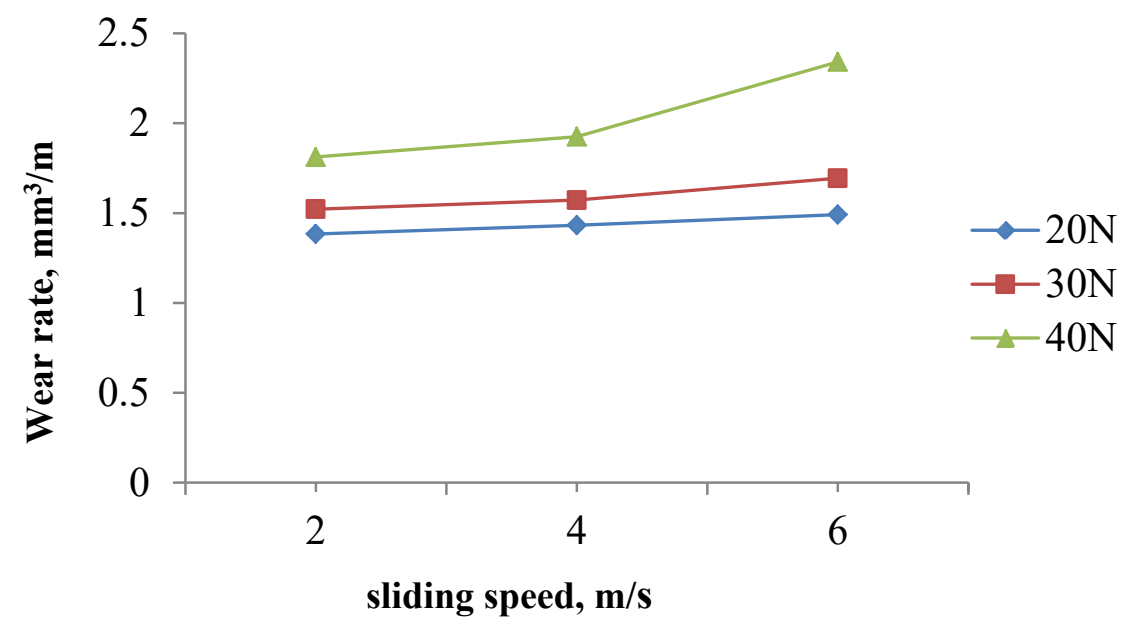

Figure4 The change in the WRvs. Sliding speed for $10 \% \mathrm{SiCp}$ composites.

The WR of the Al-composite is increased if the sliding speed will increase from 2 to $6 \mathrm{~m} / \mathrm{s}$ because of the temperature rise due to rubbing the surfaces of the composite, which is plastically constrained as shown in Figure 4. At a sliding speed of $6 \mathrm{~m} / \mathrm{s}$, the Al-composite WR curve varies to its maximum WR. Hence, the SiC will protect the matrix composite from more contact with the counter surface, which indicates the lowest COF. 
Table 4 COF with different load conditions.

\begin{tabular}{ccccccc}
\hline $\begin{array}{c}\text { Load } \\
(\mathbf{N})\end{array}$ & $\begin{array}{c}\text { Sliding speed } \\
(\mathbf{m} / \mathbf{s})\end{array}$ & $\begin{array}{c}\text { Co-efficient } \\
\text { of friction } \\
(\mathbf{C O F})\end{array}$ & $\begin{array}{c}\text { Sliding speed } \\
(\mathbf{m} / \mathbf{s})\end{array}$ & $\begin{array}{c}\text { Coefficient } \\
\text { of friction } \\
(\mathbf{C O F})\end{array}$ & $\begin{array}{c}\text { Sliding } \\
\text { speed }(\mathbf{m} / \mathbf{s})\end{array}$ & $\begin{array}{c}\text { Coefficient } \\
\text { of friction } \\
(\mathbf{C O F})\end{array}$ \\
\hline 20 & 2 & 0.448 & 4 & 0.446 & 6 & 0.443 \\
30 & 2 & 0.445 & 4 & 0.444 & 6 & 0.442 \\
40 & 2 & 0.439 & 4 & 0.436 & 6 & 0.434 \\
\hline
\end{tabular}

AMMC drysliding wear test was performed to detect COF of different loads $(20,30$ and $40 \mathrm{~N})$ and with different sliding speeds $(2,4$ and $6 \mathrm{~m} / \mathrm{s})$. The results are shown in Table 4. From Figure 5 it shows significant decreases in the value of COFof the composite under dry conditions. The decreased value of COF in the load range ( 20 to $40 \mathrm{~N}$ ) was observed because of the enforcing of silicon-carbide particles in aluminum-matrix alloys, which leads to excellent bond formation between the matrix-alloy and the silicon-carbide particles. These reinforced particles act as the fillers, and they increase fillings to reduce the contact area between the sample and the surfaces of the turntable, resulting in a lower COF.

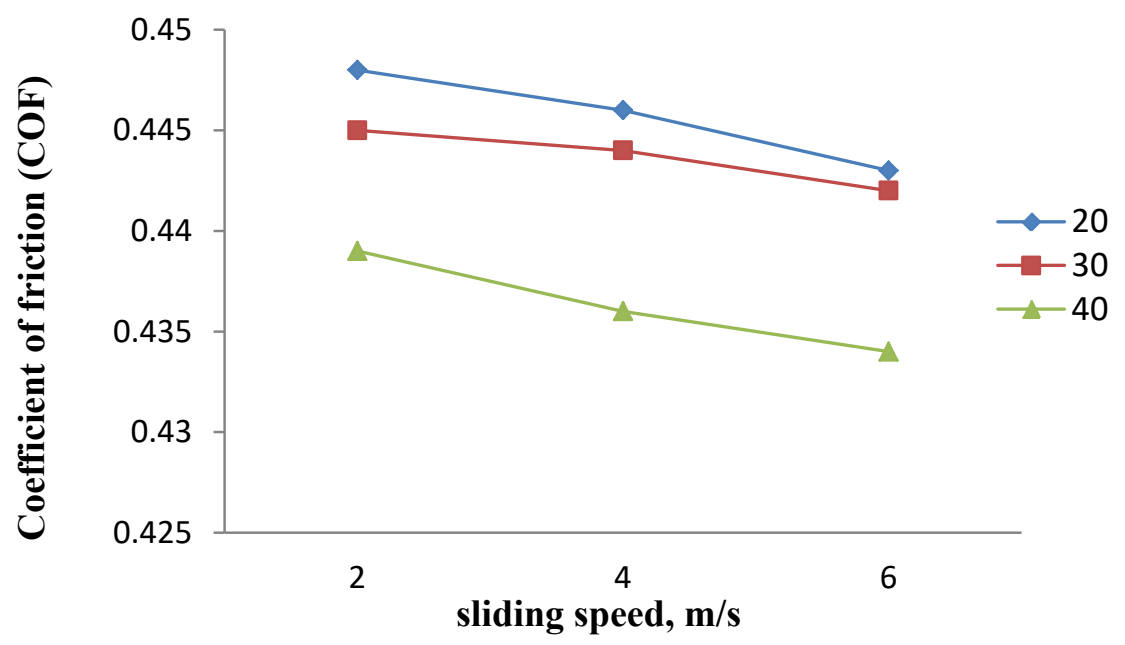

Figure5 The change in slidingspeed vs.COF for $10 \% \mathrm{SiCp}$ composites.

A comparative study of WR between past research, Mittal and Dixit [36] and the present study is given in Table 5 atafixed sliding distance of $1200 \mathrm{~m}$ anda load of $20 \mathrm{Nfor}$ differentsliding speeds of 2, 4 and $6 \mathrm{~m} / \mathrm{s}$. The following table shows the percentage decrease in WR at different sliding speeds is up to $20 \%$. Therefore, the novel AMMC has better wear resistance than other aluminum compositesdeveloped by the previous researchers.

Table 5 Comparison of WR between past and present study.

\begin{tabular}{cccc}
\hline $\begin{array}{c}\text { Sliding } \\
\text { speed }\end{array}$ & $\begin{array}{c}\text { Present study } \\
(\mathbf{P})\end{array}$ & $\begin{array}{c}\text { Past study } \\
\text { (referenced } \begin{array}{c}\text { Mittal and Dixit[36]) } \\
(\mathbf{R})\end{array}\end{array}$ & $\begin{array}{c}\text { \% decrease in wear } \\
\text { rate }\left[\frac{\boldsymbol{R}-\boldsymbol{P}}{\boldsymbol{P}} \times \mathbf{1 0 0}\right]\end{array}$ \\
\hline $2 \mathrm{~m} / \mathrm{s}$ & 1.4123 & 1.6431 & 16.34 \\
$4 \mathrm{~m} / \mathrm{s}$ & 1.5213 & 1.7216 & 13.17 \\
$6 \mathrm{~m} / \mathrm{s}$ & 1.6442 & 1.8945 & 15.22 \\
\hline
\end{tabular}




\section{Experimental design and optimization}

\section{Taguchi method}

The experimental method suggested by G. Taguchi is associated with the use of OA, influencing the processes, as well as the levels that require systematically changing the factors that conclude the experiments with minimal testing, and it will save time, capital, and resources. This method is used to develop an experiment for testing abrasive wear to obtain optimal results with a smaller number of experimental tests.

\section{Design of experiment}

The design of the experiment was to find outthe factors affecting the experimental process and to examine the minimum WR. The design was developed on the basis of OA to correlate the effects of sliding speed and load for a minimum WR and COF. The design parameter is a predictable and integral process feature, affecting and determining theworking performance of the composites.

The experimental study was carried out with a standard orthogonal array. The orthogonal array was demonstrated by examining the control parameters, levels, and their responses. The test of dry sliding wear was carried out with different parameters (load, sliding speed and sliding distance) and changed into 3 levels. As per the DOE principle, the OA must be more or equal to the sum of these wear parameters, OA (orthogonal array) L9 with 9 rows and 3 columns was selected (Table 6). The choice of an orthogonal array is based on the criteria where the DoF for the OA must be equal or greater to the sum of the verified parameters. Control factors of the wear and frictional parameters (load, sliding speed and sliding distance) were selected for this experiment. In this test, the "smaller, the better" function was selected (Table 7) for analysis of the dry sliding wear characteristics.

Table6 L9 orthogonal array of Taguchi method.

\begin{tabular}{cccc}
\hline No. of experiments & $\mathbf{1}^{\text {st }}$ Column & $\mathbf{2}^{\text {nd }}$ Column & $\mathbf{3}^{\text {rd }}$ Column \\
\hline 1 & 1 & 1 & 1 \\
2 & 1 & 2 & 2 \\
3 & 1 & 3 & 3 \\
4 & 2 & 1 & 2 \\
5 & 2 & 2 & 3 \\
6 & 2 & 3 & 1 \\
7 & 3 & 1 & 3 \\
8 & 3 & 2 & 1 \\
9 & 3 & 3 & 2 \\
\hline
\end{tabular}

Table 7 Smaller is better L9 OA.

\begin{tabular}{cccccc}
\hline Sl.no. & $\begin{array}{c}\text { Load (L) } \\
\text { in } \mathbf{~}\end{array}$ & $\begin{array}{c}\text { Sliding } \\
\text { speed (V) } \\
\text { in } \mathbf{~ m / s}\end{array}$ & $\begin{array}{c}\text { Sliding distance } \\
(\mathbf{D}) \\
\text { in } \mathbf{~ m}\end{array}$ & $\begin{array}{c}\text { Wear rate } \\
\text { in } \mathbf{~ m m}^{\mathbf{3}} \mathbf{m} \\
\left(\times \mathbf{1 0}^{-\mathbf{3}}\right)\end{array}$ & $\begin{array}{c}\text { Co-efficient } \\
\text { of friction } \\
(\mathbf{C O F})\end{array}$ \\
\hline 1. & 20 & 2 & 1000 & 1.3837 & 0.448 \\
2. & 20 & 4 & 2000 & 1.4935 & 0.425 \\
3. & 20 & 6 & 3000 & 1.7042 & 0.418 \\
4. & 30 & 2 & 2000 & 1.6435 & 0.427 \\
5. & 30 & 4 & 3000 & 2.1243 & 0.433 \\
6. & 30 & 6 & 1000 & 1.6938 & 0.442 \\
7. & 40 & 2 & 3000 & 2.9634 & 0.421 \\
8. & 40 & 4 & 1000 & 1.9256 & 0.436 \\
9. & 40 & 6 & 2000 & 3.1435 & 0.419 \\
\hline
\end{tabular}


Regression analysis solutions for the various parameter combinations were achieved by performing the orthogonal array experiments. Measurement solutions were analyzed by using commercially available MINITAB-17 software specially used in this DOE application. The impact of control parameters, i.e., normal load and sliding speed, on the WR and COF were analyzed. The experimental results were summarized using ANOVA, which is used to study the effect of considered WR and COF variables on the performance variables. By analyzing variance, it could be decided which independent factor is dominating another with a percentage of the independent variables.

\section{ANOVA results}

The results obtained for the COF, and WR from experimental trials were analysed by employing statistical ANOVA to illustrate the validation of the obtained results. It is also included to determine the significant influence of machining parameters and their interaction effects on corresponding output responses. The ANOVA table consists of degrees of freedom (DoF), sum of squares (SS), mean of squares (MS), percentage of contribution in total variation (Contribution \%), probability ( $p$ ), and $F$-value. The $p$-value and F-value are employed to determine the statistical significance and adequacy of the developed regression model. If the $p$-value for any parameter is found to be under 0.05 (i.e., at a $95 \%$ confidence level), then that input parameter may be considered as having a statistically significant influence on the corresponding output response. If the calculated F-value is lower than the standardized Fisher's value or the $p$-value is greater than 0.05 for any factor, then that parameter is considered to have no effect on the response. From Tables 8 and 9, it is observed that the proposed model for WR and COF is significant as its $p$-value and $F$-value are acceptable to the criterion of statistical significance.

Table 8 ANOVA analysis for WR.

\begin{tabular}{|c|c|c|c|c|c|c|c|}
\hline Source & DoF & Seq SS & Contribution & Adj SS & Adj MS & F-value & $P$-value \\
\hline Model & 3 & 2.56890 & $80.26 \%$ & 2.56890 & 0.85630 & 6.78 & 0.033 \\
\hline Linear & 3 & 2.56890 & $80.26 \%$ & 2.56890 & 0.85630 & 6.78 & 0.033 \\
\hline $\mathrm{L}$ & 1 & 1.98502 & $62.02 \%$ & 1.9502 & 1.98502 & 15.71 & 0.011 \\
\hline $\mathrm{V}$ & 1 & 0.05058 & $1.58 \%$ & 0.05058 & 0.05058 & 0.40 & 0.555 \\
\hline $\mathrm{D}$ & 1 & 0.53330 & $16.66 \%$ & 0.53330 & 0.53330 & 4.22 & 0.095 \\
\hline Error & 5 & 0.63190 & $19.74 \%$ & 0.63190 & 0.12638 & & \\
\hline Total & 8 & 3.20080 & $100.00 \%$ & & & & \\
\hline \multicolumn{8}{|c|}{ Model summary: } \\
\hline S & R-sq & & PRESS & R-sq (pred) & & & \\
\hline 0.355500 & $80.26 \%$ & 68 & 2.44008 & $23.77 \%$ & & & \\
\hline
\end{tabular}

$\mathrm{DoF}=$ degrees of freedom, Seq SS = sequential sum of squares, Adj SS = adjusted sum of squares, Adj $\mathrm{MS}=$ adjusted mean squares.

The load had a great impact on the WR, followed by the sliding speed. It is better to optimize the WR parameters in accordance with the given factors and level with respect to the criterion, i.e., smaller is better. Table 8 shows the percentage effect of all parameters separately, with their interactions on results. The $4^{\text {th }}$ column implies the contribution percentage of each factor and their interaction. It is concluded that the greatest influence on the WR depends on load, the coefficient of which is $62.02 \%$. The impact of sliding speed on WR is $1.58 \%$, that is, the influence of the interaction is lower than $2 \%$ with the influence of the sliding distance of $16.66 \%$. The $R$-square value is analyzed by $80.26 \%$. 


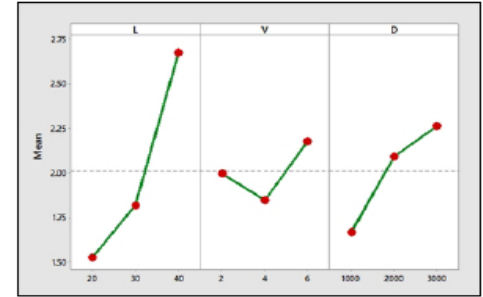

a) Main effect-plots for the means at different conditions; L, V and D of wear rate

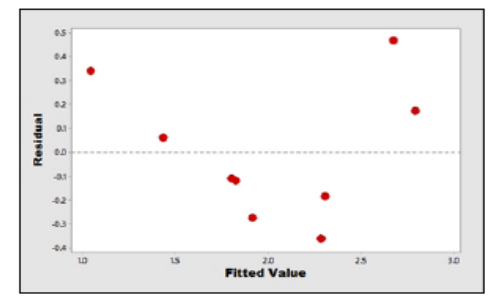

d)Residual vs. fitted-values of wear rate

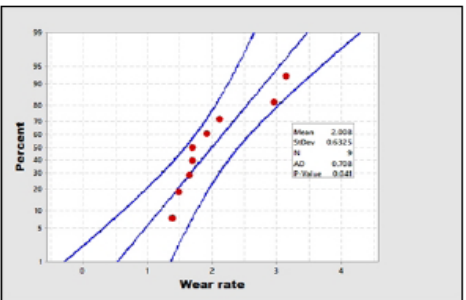

Wear rate probability plot or the linear-regression model plot for the experimental results of AMMC tested samples

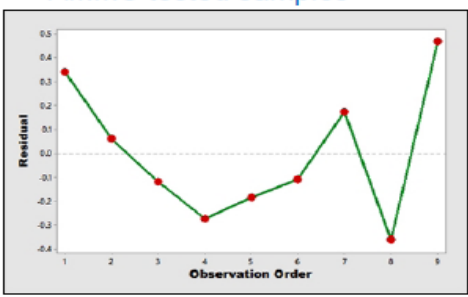

e) Residual vs. observation-order curve for the wear-rate

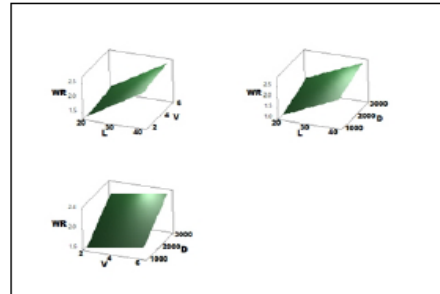

c) 3D surface-plot curve of wear rate at diff. dependencies of load, sliding-distance and sliding speed

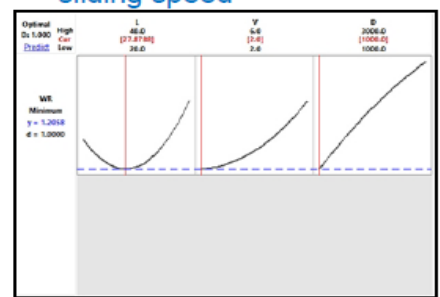

f) Optimal parameter wear

Figure 6 Regression model of WR.

The main-effects graph for the mean of the WR for which the increase in sliding speed is the main influencing factor is shown in Figure 6(a), and the WR will increase very rapidly with the wear values, and when the sliding speed increases, the WR will increase rapidly and change moderately because the sliding distance is not the main influencing factor. The probability of a linear regression line (Figure 6(b)) was calculated using the experiment's test results, and the plot compares the actual experimental results to the predicted experimental values. The probability graph shows that all points lie near the mean value because the chosen variables of the experiment are satisfactory. Since load and sliding distance had the greatest impact on the WR, a 3-D relationship dependency is shown in Figure 6(c). The lowest rate of wear was achieved at aload of $20 \mathrm{~N}$ and asliding speed of $2 \mathrm{~m} / \mathrm{s}$, while the highest value is achieved with a load of $40 \mathrm{~N}$ and a sliding speed of $6 \mathrm{~m} / \mathrm{s}$. This diagram shows the $3-\mathrm{D}$ curve of the dependencies of the wear on the surface for the different sliding distance, loads, and sliding speed.

To avoid a misleading conclusion, several diagnostic tests like adequacy, effectiveness, and goodness-of-fit were performed for proposed regression models (COF and WR). When the regression coefficient $\left(\mathrm{R}^{2}\right.$-value) approaches unity, the predicted model efficiently fits the actual data. For WR, and COF models, the $\mathrm{R}^{2}$-values $(0.8026,0.936$ and 0.936 , respectively) are near to 1 , which depicts statistical significance as well as goodness-of fit for the proposed model. Additionally, there is a good agreement between the experimental and predicted values, as illustrated in Figures 6(d) and 7(d). Hence, it is concluded that the developed model has an excellent mark of significance with good predictive ability. Figures 6(b) and 7(b) show the normal probability plot associated with the Anderson-Darling test, where the residuals are approaching a straight line, which concludesthat associated errors are normally distributed, and assumptions are not violated. Moreover, no unusual structure is apparent. The null hypothesis is that the data distribution law is normal, and the alternative hypothesis is that it is nonnormal (i.e., when the $p$-value is less than or equal to 0.05). A lower AD-statistic and larger $p$-values obtained from the Anderson-Darling test are greater than the alpha level of 0.05 (level of significance). It confirmed that the null hypothesis cannot be rejected, i.e., the data follow a normal distribution. This implies that quadratic models are adequate. Finally, it is concluded that, the developed predictive models for WR, and COF employing RSM are efficient, statistically significant, adequate, and probabilistically validated as they have a low probability value (less than 0.05 ), higher $R^{2}$-value, and larger AD-test $p$ value.

The residuals suggest that the model is systematic, Figure 6(d) and there is no need to improve the model. The regression model presented here is correct on average for all the fitted values and the random errors, i.e., $19.74 \%$ of them are toproduce the residuals that are normally distributed. Therefore, the residual falls have a uniform pattern and have a regular distribution over the entire range. Figure 6(e) denotes residuals vs. observation order plot helps to see the correlation between the error terms that are close to each other in the sequence. Residues randomly bounce around rest of the line in the 0 line. In 
general, residuals showing normal random noise around an equal 0 line residues suggest that there is no consistent correlation. The plot suggests that the assumption of independent error terms has been violated. The severity of the consequences is related to the severity of the violation. Thus, residual graphs verify the correctness of the model, taking into account the adjusted value and the order of observation.

Figure 6(f) shows the optimal parameters of WR in L, V and D, at which the WR improves due to the impact of minimum sliding distance and speed. The WR was minimized at a sliding distance of $1000 \mathrm{~m}$, a sliding speed of $2 \mathrm{~m} / \mathrm{s}$ and a load of $27.8788 \mathrm{~N}$, as proved from the figure by showing the vertical red lines. A growing trend was observed towards the $\mathrm{SiC}$ reinforcement with a greater sliding speed, which proved that the WR will decrease when higher SiC gain addition is present.

Table 9 ANOVA analysis for COF.

\begin{tabular}{cccccccc}
\hline Source & DoF & SeqSS & Contributions & AdjSS & AdjMS & F-value & $\boldsymbol{P}$-value \\
\hline Model & 3 & 0.000572 & $64.02 \%$ & 0.000572 & 0.000191 & 2.97 & 0.136 \\
Linear & 3 & 0.000572 & $64.02 \%$ & 0.000572 & 0.000191 & 2.97 & 0.136 \\
L & 1 & 0.000038 & $4.20 \%$ & 0.000037 & 0.000037 & 0.58 & 0.479 \\
V & 1 & 0.000048 & $5.39 \%$ & 0.000048 & 0.000048 & 0.75 & 0.426 \\
D & 1 & 0.000486 & $54.43 \%$ & 0.000486 & 0.000486 & 7.56 & 0.040 \\
Error & 5 & 0.000321 & $35.98 \%$ & 0.000321 & 0.000064 & & \\
\hline Total & 8 & 0.000893 & $100.00 \%$ & & &
\end{tabular}

Model summary:

S R-sq R-sq(adj) PRESS R-sq(pred)

$\begin{array}{lllll}0.0080153 & 64.02 \% & 42.44 \% & 0.0008015 & 10.23 \%\end{array}$

DoF = degrees of freedom, Seq SS = sequential sum of squares, Adj SS = adjusted sum of squares, Adj MS = adjusted mean squares.

Table 9 shows that sliding distance has the greatest impact on COF, $54.43 \%$. In addition to the sliding distance, the normal load of $4.20 \%$ and the sliding speed of $5.39 \%$ also affect the COF, and the value of R-squared is obtained at $64.02 \%$.

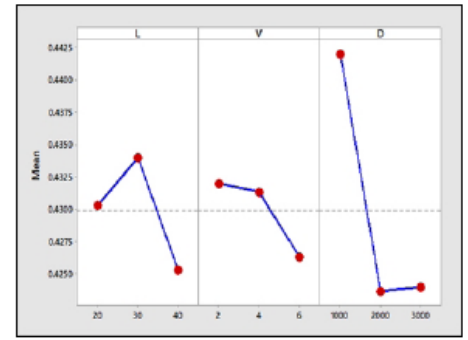

a) Main effect-plots for the means at different conditions; L, V and D of COF

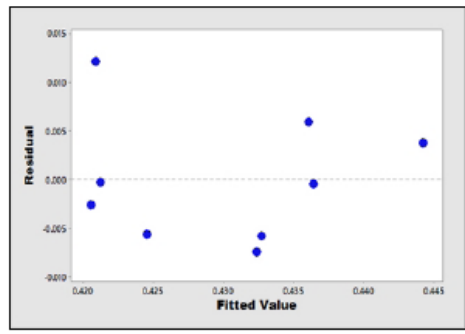

d)Residual vs. fitted-values of COF

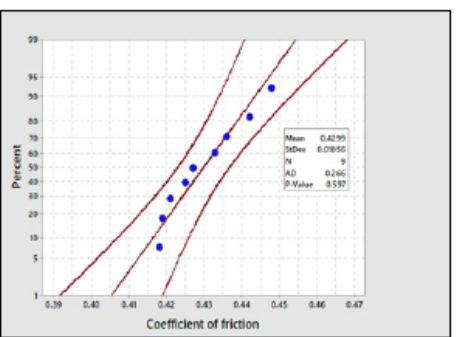

b) COF probability plot or the linear-regression model plot for the experimental results of AMMC tested samples

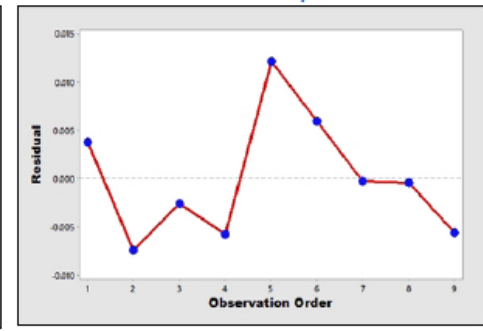

e) Residual vs. observation-order curve for the COF

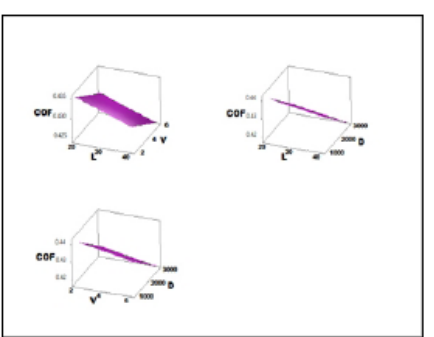

c) 3D surface-plot curve of COF at diff. dependencies of load, sliding-distance and sliding speed

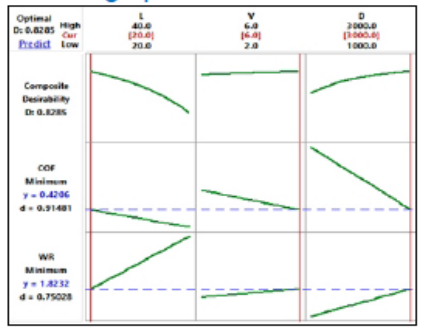

f) Optimal parameters Comparison of COF vs. wear rate

Figure7 Regression model of COF. 
Figure 7(a) depicts the graph of the main effect plot for the mean value of the COF, which indicates that as the sliding speed increases, the COF increases rapidly, and the COF decreases moderately as the sliding distance decreases. COF's probability of the linear regression line (Figure 7(b)) is a distinction between actual and predicted experimental results. The probability graph shows that all points are linear with a mean value.

The analysis of the friction coefficient parameters (Table 6) shows that the greatest influence on the friction coefficient takes place at a sliding distance of $54.43 \%$. The sliding speed effect is lower than 5.39 $\%$, while the smallest individual effect on the friction coefficient decreases under normal load of $4.20 \%$. A 3-D relationship diagram is shown in Figure 7(c). The lowest COF is achieved at $40 \mathrm{~N}$ loads and at $6 \mathrm{~m} / \mathrm{s}$ sliding speed and the highest value is achieved at $20 \mathrm{~N}$ loads and at $2 \mathrm{~m} / \mathrm{s}$ sliding speed. The $3-\mathrm{D}$ surface plot curve of COF for load, sliding distance and sliding speed is reflected in this graph. The plots, i.e., residual vs. fitted value in Figure 7(d) and residuals vs. observation order in Figure 7(e) indicate that the models are systematic and are correct on average for all similar values. $35.98 \%$ of random errors are expected to result in residuals which are uniformly distributed. Therefore, residual falls have a symmetrical pattern and have a constant distribution over the entire range.

\section{Impact of test parameters on COF and WR}

The impact of different test parameters on the WR and COF is shown in Figure 7(f). When the line of each parameter approaches the horizontal line; the parameter does not have any significant effect. On the contrary, the line thathas the greatest slope between the horizontal lines has the most significant effect on the parameters. An analysis of the impact of individual factors of the COF shows a largest slope of the load. Therefore, this slope mainly affects the COF. Also, the COF decreases with increases in load and sliding speed but increases with an increase in normal load. On the other hand, the load has more impact on the WR than others. The WR improves with increasing normal load and decreases with an increase in load and sliding speed. The minimum rate of wear occurs in the minimum normal load and sliding speed. The impacts of all the analyzed factor parameters were previously explained.

\section{Analysis of multi-linear regression models}

A linear regression-model was obtained from the MINITAB17 statistical-software and a model was developed to determine the regression equations in association between the notable parameters (applied load, sliding distance and sliding speed) through the analysis. The coefficients of regression equations are given in Tables 8 and 9. Eqs. (1) and (2) are formulated by keeping in view of the friction coefficient and wear loss based on the wt $\%$ of SiC reinforcement, the applied load, sliding speed and sliding distance. The regression-equations for the WR and COF are as follows:

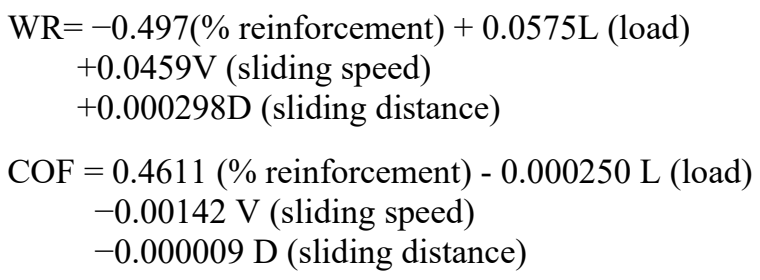

It can be seen from Eq. (1) that the coefficients associated with reinforcement content ( $\mathrm{SiC} \%)$ is negative. It indicates that the WR of the composite decreases with increasing the reinforcement. Conversely, the WR of the composite increases with decreasing $\mathrm{SiC}$ reinforcement since the coefficient associated with the applied load, sliding speed, and sliding distance are all positive.

Similarly, in Eq. (2) indicates that the coefficients associated with reinforcement content ( $\mathrm{SiC} \%)$ is positive. It indicates that the COF of the composite increases with decreasing applied load, sliding speed and sliding distance. Conversely, the decreasing of the $\mathrm{SiC}$ reinforcement since the coefficient associated with the applied load, sliding speed, and sliding distance are all positive.

These reinforced silicon carbide particles act as load bearing members as the loads increase and reduce the touch area between the specimen and the rotating disk's surfaces, which leads to lower COF $[37,38]$. Similar observations have been made by other investors [39,40]. For an AMMC, the sliding distance had the greatest impact on the WR. Consequently, the sliding distance was a primary controlled parameter that should be considered during a wear experiment, and then, with proper load application and sliding speed, it was seen that the load had the largest participation, followed by the sliding distance and sliding speed of the composite [37-40]. From the above Eqs. (1) and (2), it is summarized that the impact of each parameter corresponds to WR and COF for the tested samples were different. The increased rate 
of COF and wear were dependent on increased load and were decreased with increases in sliding speed and load. The model was established to predict the WR and COF for the tested composites presented in the equations since the points in Figure $\mathbf{6}(\mathbf{d})$ and $\mathbf{7 ( d )}$ were very close to the linear line.

\section{Conclusions}

The Taguchi orthogonal design model is best suited to examine dry sliding wear characteristics of an $\mathrm{Al}-0.5 \mathrm{Si}-0.5 \mathrm{Mg}-2.5 \mathrm{Cu}-10 \mathrm{SiC}$ composite, and this design provides an easy, systematic, and efficient design to analyze the COF and the wear parameters.

The normal load had more effect on the WR (62.02\%), while the sliding distance $(16.66 \%)$ and sliding speed $(1.58 \%)$ had a smaller effect. The relationships within each parameter had lesser effects on the WR. The COF of the tested composites also mainly depends on the sliding distance $(54.43 \%)$ and significantly less influence on the sliding speed $(5.39 \%)$ and load $(4.20 \%)$. The relationships within each parameter had a fewer effects on the COF. The optimal test parameters for both WR and COF were calculated, and there are good contracts between the predictive and actual WR as well as in the COF. The predictive models developed for various dry sliding wear performance characteristics employing response surface methodology are effective in terms of adequate, statistically significant, and probabilistically validate because of their higher $\mathrm{R}^{2}$-values, $P$-values less than 0.05 and larger $\mathrm{AD}$-test $P$-values. The microstructure results show that the additional percentage of $\mathrm{SiC}$ increases the wear resistance. The COF of the composite is lesser than that of the aluminum. With the increase in sliding speed and applied load, the WR of composite increases. The WR decreases with the rise in wt $\%$ of reinforced particles. It clearly shows that the $\mathrm{SiC}$ and silicon present in the AMMC are resistant to high wear.

Finally, it is stated that the proposed predictive model for the wear indicator using RSM is effective, statistically significant, relevant, and also probabilistically verified.

\section{References}

[1] RK Behera, BP Samal, SC Panigrahi and KK Muduli. Microstructural and mechanical analysis of sintered powdered aluminium composites.Adv. Mater. Sci. Eng. 2020; 2020, 1893475.

[2] RK Behera,B PSamal andS C Panigrahi. Manufacture of die and their designing parameters for sintered AMC product. Mater. Tech. 2019; 107, 605.

[3] RK Behera, SC Panigrahi, BP Samal and PK Parida. Mechanical properties and micro-structural study of sintered aluminium metal matrix composites by $\mathrm{P} / \mathrm{M}$ technique. J. Mod. Manuf. Syst. Tech. 2019; 3, 089-097.

[4] A Mazahery andMO Shabani.Study on microstructure and abrasive wear behavior of sintered Al matrix composites. Ceram. Int. 2012; 38, 4263-9.

[5] C Garcla-Cordovilla, J Narciso andE Louis.Abrasive wear resistance of aluminium alloy/ceramic particulate composites. Wear 1996; 192, 170-7.

[6] BP Samal, AK Misra, SC Panigrahiand Sc Mishra. A Novel technique for improved recovery of Mg--Analysis of the microstructure and physical properties. J. Mater. Metall. Eng. 2013;3, 1-7.

[7] S Banthia, S Sengupta, S Das and $\mathrm{K}$ Das. $\mathrm{Cu}, \mathrm{Cu}-\mathrm{SiC}$ functionally graded coating for protection against corrosion and wear. Surf. Coat. Tech. 2019; 374, 833-44.

[8] J Sethi, S Das andK Das. Development of low expansion and high strength aluminum matrix hybrid composite. In: A Ratvik (Ed.). Light metals. The minerals, metals \& materials series. Springer, Cham, 2017, p.187-93.

[9] A Mandal, K Das andS Das.Characterization of microstructure and properties of Al-Al3Zr-Al2O3 composite. Bull. Mater. Sci. 2016; 39, 913-24.

[10] AK Pradhan and S Das.Dry sliding wear and friction behavior of Cu-SiCnanocomposite coating prepared by pulse reverse electrodeposition. Tribol. Trans. 2014; 57, 46-56.

[11] S Das, K Das and SDas.Abrasive wear behavior of Al-4.5 wt\%Cu/(Zircon Sand + Silicon Carbide) hybrid composite. J. Compos.Mater. 2009; 43, 2665-72.

[12] SC Lim, M Gupta, L Renet and JKM Kwokb.The tribological properties of Al-Cu/SiCp metalmatrix composites fabricated using the rheocasting technique. J. Mater. Process. Tech. 1999; 89-90, 591-6.

[13] G Dixit andMM Khan.Sliding wear response of an aluminium metal matrix composite: Effect of solid lubricant particle size. Jordan J. Mech. Indus. Eng. 2014; 8,351-8.

[14] S Basavarajappa, G Chandramohan, R Subramanian and A Chandrasekar. Dry sliding wear behaviour of Al 2219/SiC metal matrix composites. Mater. Sci-Poland 2006; 24, 358-66.

[15] S Ghosh, P Sahoo andG Sutradhar. Wear behaviour of Al-SiCpmetal matrix composites and optimization using Taguchi method and grey relational analysis. J. Miner. Mater. Char. Eng. 2011; 11, 1085-94. 
[16] M Uzkut. Abrasive wear behavior of SiCp-reinforced 2011 Al-alloy composites. Mater. Tech. 2013; 47, 635-8.

[17] M Narayan, MK Surappa and BNP Bai. Dry sliding wear of Al alloy 2024- $\mathrm{Al}_{2} \mathrm{O}_{3}$ particle metal matrix composites. Wear 1995; 181-183, 563-70.

[18] BG Park, AG Crosky and AK Hellier. Material characterization and mechanical properties of $\mathrm{Al}_{2} \mathrm{O}_{3}$-Al metal matrix composites. J. Mater. Sci. 2001; 36, 2417-26.

[19] BK Prasad.Investigation into sliding wear performance of zinc-based alloy reinforced with SiC particles in dry and lubricated conditions. Wear 2007; 262, 262-73.

[20] J Salguero, J Manuel, SV Martinez and Batista. Application of pin-on-disc techniques for the study of tribological interferences in the dry machining of A92024- $\mathrm{T}_{3}$ (Al-Cu) alloys. Materials 2018 ; 11, 1236.

[21] H Zhang, Z Zhang andK Friedrich. Effect of fiber length on the wear resistance of short carbon fiber reinforced epoxy composites.Compos. Sci. Tech. 2007; 67, 222-30.

[22] D Aruri, K Adepu, KAdepu and K Bazavada. Wear and mechanical properties of 6061-T6 aluminum alloy surface hybrid composites $[(\mathrm{SiC}+\mathrm{Gr})$ and $(\mathrm{SiC}+\mathrm{Al} 2 \mathrm{O} 3)]$ fabricated by friction stir processing. J. Mater. Res. Tech. 2013; 2, 362-9.

[23] H Alrobei. Effect of different parameters and aging time on wear resistance and hardness of SiCB4C reinforced AA6061 alloy.J. Mech. Sci. Tech. 2020; 34, 2027-34.

[24] S Pradhan, S Ghosh, TK Barman and P Sahoo. Tribologicalbehavior of Al-SiC metal matrix composite under dry, aqueous and alkaline medium. Silicon 2017; 9, 923-31.

[25] SA Kori and TM Chandrashekharaiah. Studies on the dry sliding wear behaviour of hypoeutectic and eutectic Al-Si alloys. Wear 2007; 263, 745-55.

[26] O Ismail.Abrasive wear behavior of various reinforced AA6061 matrix composites produced with hot pressing process: A comparative study. Materialwiss. Werksttech. 2017; 48, 589-99.

[27] M Singla, L Singh and V Chawla.Study of wear properties of Al-SiCcomposites.J. Min. Mater. Char. Eng. 2009; 8, 813-9.

[28] KR Padmavati and R Ramkrishnan. Tribological behaviour of aluminium hybrid metal matrix composite. Procedia Eng. 2014; 97, 660-7.

[29] B Stojanovic, M Babic, S Velickovic and J Blagojevic. Optimization of wear behaviour in aluminium hybride composites using Taguchi method. In: Proceedings of the $14^{\text {th }}$ International Conference on Tribology, Belgrade, Serbia. 2015, p. 81-6.

[30] B Stojanovic, J Blagojevic, M Babic, S Velickovic and S Miladinovic.Optimizations of hybrid aluminum composites wear using Taguchi method and artificial neural network. Ind. Lubr. Tribol. 2017; 69, 1005-15.

[31] R Yousefi, MA Kouchakzadeh, J Rahiminasab and MA Kadivar. The influence of SiCparticles on tool wear in machining of $\mathrm{Al} / \mathrm{SiCmetal}$ matrix composites produced by powder extrusion. $A d v$. Mater. Res. 2011; 325, 393-9.

[32] P Serrao, R Prabhu, BP Chiranth and Y Mohammed. Application of Taguchi method to predict the abrasive wear behavior of CP titanium. J. Mech. Eng. Autom. 2016; 6, 13-7.

[33] N Radhika, A Vaishnavi and GK Chandran. Optimisation of dry sliding wear process parameters for aluminium hybrid metal matrix composite. Tribol. Ind. 2014; 36, 188-94.

[34] S Basavarajappa, G Chandramohan and JP Davim. Application of Taguchi techniques to study dry sliding wear behaviour of metal matrix composites. Mater. Des. 2007; 28, 1393-8.

[35] B Stojanovic, A Vencl, I Bobic, S Miladinovic and J Skerlic. Experimental optimisation of the tribological behaviour of $\mathrm{Al} / \mathrm{SiC} / \mathrm{Gr}$ hybrid composites based on Taguchi's method and artificial neural network. J. Braz. Soc. Mech. Sci. Eng. 2018; 40, 311.

[36] P Mittal and G Dixit. Dry sliding wear behaviourof 2014 aluminium alloy reinforced with SiC composite. Int. J. Eng. Res. Tech. 2016; 5, 147-53.

[37] A Mazahery and MO Shabani.Study on microstructureand abrasive wear behavior of sintered Al matrix composites. Ceram. Int. 2012; 38, 4263-9.

[38] KK Singh, S Singh and AK Shrivastava. Study of tribological behavior of silicon carbide based aluminum metal matrix composites under dry and lubricated environment. Adv. Mater. Sci. Eng. 2016; 2016, 3813412.

[39] ZF Zhang, LC Zhang and YW Mai.Particle effects onfriction and wear of aluminium matrix composites. J. Mater. Sci. 1995; 30, 5999-6004.

[40] S Wilson and AT Alpas. Wear mechanism maps for metalmatrix composites. Wear 1997; 212, 41-9. 